\title{
EXIT STRATEGIES FOR COVID 19: AN ISM AND MICMAC APPROACH
}

\author{
Debashree Das', Avik Datta2, Patanjal Kumar3 \\ 1. Faculty of Management Studies, University of Delhi, India \\ 2. Bureau of Indian Standards, New Delhi, India \\ 3. Indian Institute of Management-Rohtak, Haryana, India.
}

Correspondence: debashree763@gmail.com

\begin{abstract}
COVID 19 pandemic is the worst crisis that mankind has seen since World War-II. It has exposed glaring loopholes in the healthcare system and led to a global health crisis. In absence of any specific treatment or vaccine, countries began to enforce strict lockdown measures leading to a complete shutdown of economic activities. The purpose of this study is to identify key exit strategies that can be implemented to mitigate the impacts of COVID 19. Identification and categorisation of parameters have been achieved using multi criterion decision making techniques of Interpretive Structural Modelling (ISM) and Cross-impact matrix multiplication applied to classification MICMAC analysis.
\end{abstract}

The study highlights a classification of key strategies based on their driving power and dependence which may enable Government to strengthen the disease surveillance system and effectively reduce the impact of the disease. The findings of the study suggest that Environmental Sustainability and Human Well-being; Online Awareness and Capacity Building Programme; Graded SurveillanceTargeted Restrictions and Stricter norms for Inter-State Mobility; and Harmonization between Centre, State and Local Authorities are the most important strategies that needs to be factored in while planning for the post lockdown economic recovery. With countries eager to resume economic activities, the strategies identified in our study can assist the governments and policymakers across the world in devising their exit plans while giving due consideration to each of the strategies to counter the disruptions brought about by the COVID 19 pandemic.

\section{KEYWORDS}

COVID 19, Exit Strategy, Interpretive Structural Modelling (ISM), Cross-impact matrix multiplication applied to classification MICMAC

\section{INTRODUCTION}

COVID 19 is an infectious respiratory disease caused by severe acute respiratory syndrome coronavirus (SARS-COV 2 ). The disease initially came to light in Wuhan in December 2019 and since then has spread to all continents except Antarctica. SARS-CoV-2 pandemic has affected more than 3 million people worldwide $(3,517,345$ confirmed cases and 243,401 reported deaths. [1] Countries worldwide have struggled to break the chain of transmission leading to exponential growth of confirmed cases and deaths. The rapid spread of COVID-19 has forced countries worldwide to limit travel, quarantine citizens, implement emergency lockdown plans and apply social distancing norms. This has resulted in a near shutdown of almost all economic activities which has the potential to drive economies towards the recessionary trap.

Ramifications of this pandemic is multi-faceted. With no breakthrough of any vaccine or effective anti-viral 
treatment, countries have relied on modern molecular diagnostics and electronic surveillance, contact tracing through artificial intelligence for identification of people at potential risk. Several countries are working hard to counter the effect of this viral disease by experimenting with several traditionally practised medical techniques and methods. Thus, to avoid any further escalation of the disease, most governments worldwide have resorted to stringent norms of practising social distancing which include quarantine and travel restrictions. This method of social distancing and restricted mobility is a desperate attempt made by countries to flatten the slope of the curve and to buy time for preparing the health care systems to respond to the pandemic. However complete shut-down strategy has resulted in supply chain disruptions and liquidity shocks. This has been particularly harmful for developing economies with limited resources to absorb prolonged national 'lockdowns' and can further escalate the recessionary strain due to the negligible economic productivity.

Thus, it is important to have a plan for reactivating the society and to devise exit strategies to tackle the economic downturn, resume work and production, open up all the sectors of the economy with targeted travel restrictions and policy resolutions. A strategy or 'roadmap' is required to be framed for deescalating the lockdown measures based on epidemiological indicators to minimise the impacts of this pandemic. This research highlights potential exit strategies which are likely to be influential in reducing the catastrophic effect of COVID-19. The main objectives of this paper are to provide a conceptual framework using Interpretive Structural Modelling (ISM) approach and to identify the key strategic intervention that could be implemented by the Government in the post-lockdown period. In this study the following strategies have been suggested to counter the pandemic that has led to severe global socioeconomic disruption-

1. Financial emergency response plan (S1)

2. Harmonization between centre, state and local authorities (S2)

3. Social cooperation and trust (S3)

4. Environmental sustainability and human well-being (S4)

5. Resumption of economic activities and trade facilitation (S5)

6. Graded surveillance: Targeted restrictions and stricter norms for inter-state mobility (S6)
7. Reducing community transmission through universal masking policy and optimal social distancing (S7)

8. Economic recovery (S8)

9. Research and development in healthcare sector (S9)

10. Augmenting healthcare infrastructure (S10)

11. Online awareness and capacity building program (S 11 )

These exit strategies can be the guiding light towards economic revival. Through interpretive structural modelling (ISM) and cross-impact matrix multiplication applied to classification (MICMAC) approach we analyse the interrelationship between these potential strategic interventions that can be factored in by the government in their post lockdown planning. The following research objectives are proposed that needs to be evaluated in detail to understand the effectiveness of the suggested strategies that can reduce the COVID 19 distress.

Proposition 1: Identification of the major exit strategies that can be devised to combat COVID 19 pandemic.

Proposition 2: Evaluate the inter-relationships among these strategic interventions by the Government for an effective action plan to combat the crisis.

Proposition 3: Segmenting the exit strategies based on their driving power and degree of dependence and evaluating the relative importance of the strategies to enable policymakers to frame the pandemic response plan.

\section{LITERATURE REVIEW}

The universal policy of "Global-Lockdown" has been effective in deaccelerating the rate at which the worldwide statistics of COVID 19 cases have beenreported, but it cannot be sustainable in the long-run as it has already crippled our economy towards recession. Thus, to revive the economy more inclusive and sustainable exit strategies have to be framed which requires comprehensive analysis to find out the interrelationship among them in order to identify the key or triggering strategies that can be prioritized for a steady economic growth. These strategies are listed below with definitions and references.

\subsection{FINANCIAL EMERGENCY RESPONSE PLAN}

Almost $30 \%$ of countries are believed to have no COVID-19 national preparedness and response plans. [1] The COVID19 Solidarity Response Fund for WHO has been initiated 
which is managed by the UN Foundation and the Swiss Philanthropy Foundation.This crowdfunding initiative has been started to raise money for the vulnerable and developing economies to provide support to the individuals and business in response to the outbreak of the novel coronavirus disease 2019 (COVID-19) pandemic. [2]

Another landmark bill that was passed as a law by the Federal Reserve of USA which aims to provide fiscal relief to the states and to stabilize the economy, Coronavirus Aid, Relief, and Economic Security Act ('CARES Act') by providing direct payments and fiscal benefits to individuals suffering hardship due to the pandemic and the subsequent economic disruption. [3]

Thus, with the rapid escalation of the COVID 19 crisis, nations worldwide need to expedite a financial emergency plan to strengthen national and state health systems, to provide livelihood security and implement strategic preparedness initiatives to safeguard the economy.

\subsection{HARMONIZATION BETWEEN CENTRE, STATE AND LOCAL AUTHORITIES}

Harmonization of fiscal relations between centre, state and local bodies is considered to be one of the most integral part of any democracy, but with the spread of the novel virus and increasing degree of financial and economic volatility it has led to a situation of intra-governmental conflicts. Federations are increasingly facing complex policy challenges, from managing funds to limiting the catastrophic effect of this contagious disease. With the inception of COVID 19, this intra-governmental conflict is further aggravated in major economies around the world. $[4,5]$

This network of overlapping local governments with varied levels of hierarchical setup can be harmonized through mutual cooperation and collaboration. The local government authority which directly deals with the management of the front line government personnel (hospital, fire, police, essential service providers) responsible for pandemic management in the special districts should implement the directives set up by the state and federal government. Even the state and the central government should be devoid of any opportunistic political motivations and authoritarianism, they should work in harmony with voluntary cooperation and compliance from the citizens. [6] Thus, the COVID-19 pandemic can be tackled through efficient public finance management and intra-governmental cohesion.

\subsection{SOCIAL COOPERATION AND TRUST}

Every contagious disease is associated with a degree of stigma and considerable discrimination within the society. Similarly, the level of stigma associated with COVID-19 hinders the mitigation of the disease and creates a sense of anxiety, and fear among the public. To safeguard the frontline workers and public health care support staff several measures are suggested by the UNICEF. [7]

The social stigma undermines the social cohesion and can lead to psychological distress among people and health problems. Tensions between stigma mitigation can be eliminated through online awareness of the chronic disease through varied multimedia sources and engaging with affected communities, build empathy and social justice among people. [8] Social harmony builds trust which further increases the degree of participation and community engagement. This amplified positivity reinforced in the attitude of the local community may prove to be highly beneficial to the successful containment of the COVID-19 pandemic. [9]

\subsection{ENVIRONMENTAL SUSTAINABILITY AND HUMAN WELL-BEING}

To combat the spread of COVID 19, the global lockdown implemented by major economies across the globe resulted in drastic effects on social and economic fronts. The shutdown of major industries not only crippled the economic productivity and aggravated the financial crisis but it also led to negative psychological effects on individuals. The severity of psychological distress across population during the lockdown period could be attributed to depression, post-traumatic stress, confusion and boredom, frustration and anxiety which were mostly stimulated due to social isolation, fear of infection and low immunity, inadequate food supplies, misinformation on social media, financial loss, and stigma. [10-12] However, this lockdown also led to some positive effect with respect to the ecological sustainability and environmental conditions. The data released by NASA (National Aeronautics and Space Administration) [13] indicated that the pollution level in some of the major economies affected by COVID-19 such as Wuhan, Italy, Spain and USA have reduced up to $30 \%$.

Thus, the fatality and threat associated with global pandemic have a serious consequence on the human 
health as well as causing economic downturn but has also led to a considerable positive impact on the environmental sustainability.

\subsection{RESUMPTION OF ECONOMIC ACTIVITIES AND TRADE FACILITATION}

The current public health emergency has not only disrupted the domestic economic activity but also led to cross-border trade disturbances. International trade is one of the integral parts of economic growth, the COVID 19 outbreak has led to disruption to world trade, affecting both the supply and demand side of the global economy. The global lockdown has further imposed restrictions on labour mobility, further leading to stoppage in non-essentia manufacturing activities.

With the growing uncertainty of pandemic's severity and the protectionist trade policy of high tariffs and non-tariff barriers to impede foreign exports, the countries pose the risk of further worsening the global healthcare systems. With the spread of the disease there is sharp increase in the demand for medical supplies beyond the competencies of domestic production level, the nations are even exposed to the problem of food crisis without any support of the international supply chains in the agricultural and food industries, the international tourism and hospitality sector has also suffered massively with restrictions on air travel and sealing of international borders. [14-17]

Hence, to safeguard food security and strengthen international trade relations resumption of cross-border economic activities and mutual cooperation is required to break the economic barriers in the times of crisis. A greater harmony in international relations and national integration can help economies evolve from the crisis of the COVID-19 pandemic.

\subsection{GRADED SURVEILLANCE: TARGETED RESTRICTIONS AND STRICTER NORMS FOR INTER - STATE MOBILITY}

As a precautionary measure to prevent further spread of Coronavirus, most economies restricted the inter-state and inter-country mobility by imposing travel bans, lockdowns, and movement restrictions of any good or services by sealing the domestic and international borders. The policy intervention to implement travel quarantine, restriction on labour migration and sealing all the human mobility corridors were imitated from the Wuhan crisis to contain the spread of COVID-19 and to mitigate the epidemic from further spreading to vulnerable sections of the society. These approaches were legally enforced to help with
COVID-19 containment to avoid further national and international spread of the epidemic. [18-20]

Therefore, to mitigate the epidemic it is important to take into account the stringent travel restrictions on any mobility with the government provision to relax certain guidelines for resumption of essential services after periodic review by the State.

\subsection{REDUCING COMMUNITY TRANSMISSION THROUGH UNIVERSAL MASK POLICY AND OPTIMAL SOCIAL DISTANCING}

With the COVID-19 pandemic exponentially growing worldwide, the policy of universal face mask and optimal social distance have been mandated byWorld Health Organization (WHO) to be critically important to prevent the virus from further spreading in the social network.

Social distancing is the practice of increasing the physical space between two or more individuals in order to decrease the chance of spreading illness. According to the Centre for Disease Control and Prevention (CDC) of USA, the spacing guideline of 6 feet or 1.5 metres have been suggested to decrease the spread of COVID-19. [21] Besides this, the updated guidelines of CDC have also strongly endorsed universal public masking in crowded public spaces and enclosed workplaces. [22-24]

In the spread of virus largely due to the close community gathering and social network contamination, these strategic interventions by the Government will prove to be beneficial from spreading the virus in the densely populated areas around the world.

\subsection{ECONOMIC RECOVERY}

COVID-19 pandemic has led to a devastating global shock that has drastically reduced the demand globally and also resulted in a supply shock. Such shocks have drifted the economies to a recessionary trajectory which require immediate bailout reforms through fiscal and monetary stimulus. With this massive international financial crisis that has wiped off share markets value globally and the global GDP prediction of 2.4 percent; massive unemployment and widespread income inequality; decreasing purchasing power of the consumers; major sectoral stagnation and bankruptcy, and the threat of escalating mortality rates due to the pandemic. This financial crash has downgraded the entire economy and scaled down to a lowest point. The health crisis has not only increased the death rate but also further created a recessionary pressure. Thus, the repercussions of the COVID-19 outbreak for businesses, workers and supply chains could be severe. [25-28] 
Thus, to safeguard the economy from the social and economic risks of epidemic the Government needs to devise a balanced strategic intervention.

\subsection{RESEARCH AND DEVELOPMENT IN THE HEALTHCARE SECTOR}

As confirmed by WHO, there exists no traditional vaccines that has potential to protect against the novel coronavirus. The SARS-COV-2 virus is a unique virus which requires rapid research and development initiatives worldwide and clinical trials to invent a new vaccine that resolves this widespread impact of COVID 19. Therefore, researchers all over the world are required to capitalize on their previous experience and knowledge of dealing with similar pandemic outbreaks such as Ebola virus disease, SARS-CoV and MERS-CoV and develop a R\&D plan to develop the vaccine against 2019-nCoV.

More than 100 organisations worldwide have published genomes to develop the vaccine against SARS-CoV-2 and more than 500 clinical trials have been conducted on all COVID 19 patients who were registered by the World Health Organisation in the Clinical Trial Registry. [29, 30] Thus, there is an urgent need to facilitate these research organizations and institutions with substantial research funds and infrastructure.

\subsection{AUGMENTING HEALTHCARE INFRASTRUCTURE}

With the escalated number of cases each day, every country is faced with the dilemma of surge capacity for intensive critical units and other integral medical services. Thus, government interventions are required to estimate the number of critically ill patients and adapt surge capacity by establishing more isolation and containment centres for treatment before the healthcare system is overwhelmed. [31]

There is a growing need to develop an advanced digitized surveillance system through $\mathrm{Al}$-powered temperature screening method, using drones for surveillance instead of deploying personnel, peer-to-peer contact tracing methods of patient tracking, provision of telemedicine services and virtual medical diagnosis for an efficient management of the healthcare system. [32]

\subsection{ONLINE AWARENESS AND CAPACITY BUILDING PROGRAM}

Social media and other platforms have significantly helped in public dissemination of information and raise awareness related to COVID-19 infection with respect to personal hygiene practices, social norms and guidance to limit the spread of disease on a large scale, busting several myths and misinformation floated through the online portals and also helped raising citizen engagement and participation with the Government to tackle the disease. Social media has been helpful in easing the psychological distress due to isolation and enabled connectivity among communities during this uncertain time of crisis.

With respect to capacity building program, all face-to-face interactions have been transformed into virtual meetings and the curriculum delivery from the traditional classroom environment has been replaced with distance/online programs. Thus, the massive disruption in teaching-learning process due to the COVID-19 pandemic should not hinder the institutions and it should explore digital platforms to encourage off-site knowledge sharing through extensive training programs, collaborative research, and web-based education technologies using Massive Open Online Courses (MOOCs). [33-35]

\section{METHODOLOGY AND RESULTS}

In this study interpretative structural modelling (ISM) methodology has been used to develop a structural model of the government's strategic interventions which are used as a proxy for the critical success factors of the analysis and determination of relationship between the dependent strategies and driving strategies.

\subsection{INTERPRETIVE STRUCTURAL MODELLING (ISM)}

The concept of interpretative structural modelling is used for analysis of complex socio-economic problems. In this model a set of questions (parameters) which define the scope of the problem are presented to the participants. [36]

The multi-faceted nature of COVID 19 raises the need to devise a mix of strategies rather than adopting a single policy in isolation for safeguarding human well-being and long-term sustainability. Thus, it is critically important to evaluate the effectiveness of each strategy and analyse the direct and indirect influence of these strategies for smooth switch over to the post lockdown period. For a holistic view of the crisis the need of the hour is to investigate the situation in a much more inclusive way by taking into consideration all possible parameters collectively rather than relying on one individual parameter. Therefore, ISM develops insights into collective understandings of these relationships. 
The total interpretive structural modelling has been applied to evaluate the factors that affects the epidemiological characteristics of pandemic COVID-19. [37] Besides the need to understand the factors leading to the spread of the virus, at this juncture when all economies around the globe are contemplating on the possible measures to minimize the economic loss, it is of critical importance to understand varied exit strategies that can be devised to safeguard the economy from slipping further into recession. Through the application of ISM, in our study we have evaluated varied policy measures and strategic interventions that can be implemented to improve the widespread economic distress and understand the linkages among these strategies and prioritize them based on their effectiveness.

The various steps involved in the ISM technique are:

- Step 1: Identification of elements

Identification of relevant strategies to combat the impact of COVID 19 have been achieved through extensive literature review and expert opinions that were collected through brainstorming sessions and group discussions.

- Step 2: Establishing a contextual relationship

The inter-relationship between various strategies were determined for all the strategies based on responses received from academicians, researchers, and policymakers.

- $\quad$ Step 3: Developing a structural self-interaction matrix (SSIM) of elements

A pair-wise relationship between these strategies were established and the correlation matrix was constructed based on the expert judgement.

- Step 4: Development of a reachability matrix from selfinteraction matrix (SSIM) and transitivity check

An initial reachability matrix is constructed based on using 0 and 1 based on responses received in steps 1 and 2. After checking the matrix for transitivity, a final reachability matrix was constructed that summarizes all the possible combination of the strategies.

- $\quad$ Step 5: Level partitioning of reachability matrix

The parameters are placed level wise and the reachability and antecedent sets are prepared for all parameters.

- Step 6: Development of diagraph

A directed graph or diagraph is drawn after placing the parameters in their respective levels. The direct links are drawn based on relationship as per the reachability matrix.
Only those transitive links whose interpretation is crucial are retained.

\section{- Step 7: ISM hierarchical graph}

The resultant digraph was converted into an ISM graph, by replacing element nodes with statements. This flowchart provides the summary of all the iterations based on the relative weightage and importance of the strategies proposed to be implemented by the Government post the lockdown period. This ISM model was further checked for any conceptual inconsistency and validity.

The steps used to develop ISM model have been highlighted and discussed in detail below:

\subsection{STRUCTURAL SELF-INTERACTION MATRIX (SSIM)}

To analyse appropriate inter-relationship between strategies a contextual relationship of "leads to" is taken. For developing these contextual relationships among variables, expert opinions based on detailed online group discussion and focus group interviews have been undertaken.

Based on their responses, the relationship between different strategies and for expressing their association with one-another, four symbols have been used to denote the direction of relationship between the parameters $i$ and j (here $\mathrm{i}<\mathrm{j}$ ):

- $\quad$ : Strategy i leads to Strategy j;

- $\quad$ A: Strategy j leads to Strategy i;

- $\mathrm{X}$ : Strategy $\mathrm{i}$ and $\mathrm{j}$ leads to each other;

- O: Strategy i and j are unrelated.

\subsection{REACHABILITY MATRIX}

The entries of structural self interaction matrix (SSIM) are replaced by 0 and 1 to form an initial reachability matrix. $V$, $O, A, X$ entries of SSIM are mapped as per the following rules:

- If the (i, j) entry in the SSIM is $V$, then (i, j) entry in the reachability matrix becomes 1 and the $(j, i)$ entry becomes 0 .

- If the (i, j) entry in the SSIM is $A$, then (i, j) entry in the reachability matrix becomes 0 and the $(j, i)$ entry becomes 1.

- If the $(i, j)$ entry in the SSIM is $X$, then $(i, j)$ entry in the reachability matrix becomes 1 and the $(j, i)$ entry also becomes 1 . 
- If the $(i, j)$ entry in the SSIM is $O$, then $(i, j)$ entry in the reachability matrix becomes 0 and the (j, i) entry also becomes 0. [Do not delete section break]

Based on contextual relationships the SSIM is developed in Table 1:

TABLE 1: STRUCTURAL SELF INTERACTION MATRIX (SSIM)

\begin{tabular}{|c|c|c|c|c|c|c|c|c|c|c|c|}
\hline STRATEGY & S1 & S2 & S3 & S4 & S5 & 56 & S7 & S8 & 59 & S10 & S11 \\
\hline S1 & $x$ & A & V & 0 & 0 & A & 0 & 0 & 0 & 0 & 0 \\
\hline S2 & & $x$ & V & A & 0 & V & 0 & 0 & 0 & 0 & $x$ \\
\hline S3 & & & $x$ & 0 & 0 & 0 & V & 0 & 0 & 0 & 0 \\
\hline S4 & & & & $x$ & 0 & 0 & 0 & 0 & 0 & 0 & 0 \\
\hline S5 & & & & & $X$ & 0 & A & V & 0 & 0 & 0 \\
\hline S6 & & & & & & $x$ & O & O & V & O & A \\
\hline S7 & & & & & & & $X$ & 0 & 0 & A & 0 \\
\hline S8 & & & & & & & & $X$ & 0 & 0 & 0 \\
\hline s9 & & & & & & & & & $x$ & V & 0 \\
\hline$S 10$ & & & & & & & & & & $x$ & O \\
\hline S11 & & & & & & & & & & & $x$ \\
\hline
\end{tabular}

Following above rules, the initial reachability matrix for the identified strategies is highlighted in Table 2:

\section{TABLE 2: INITIAL REACHABILITY MATRIX}

\begin{tabular}{|l|l|l|l|l|l|l|l|l|l|l|l|}
\hline STRATEGY & S1 & S2 & S3 & S4 & S5 & S6 & S7 & S8 & S9 & S10 & S11 \\
\hline S1 & 1 & 0 & 1 & 0 & 0 & 0 & 0 & 0 & 0 & 0 & 0 \\
\hline S2 & 1 & 1 & 1 & 0 & 0 & 1 & 0 & 0 & 0 & 0 & 1 \\
\hline S3 & 0 & 0 & 1 & 0 & 0 & 0 & 1 & 0 & 0 & 0 & 0 \\
\hline S4 & 0 & 1 & 0 & 1 & 0 & 0 & 0 & 0 & 0 & 0 & 0 \\
\hline S5 & 0 & 0 & 0 & 0 & 1 & 0 & 0 & 1 & 0 & 0 & 0 \\
\hline S6 & 1 & 0 & 0 & 0 & 0 & 1 & 0 & 0 & 1 & 0 & 0 \\
\hline S7 & 0 & 0 & 0 & 0 & 1 & 0 & 1 & 0 & 0 & 0 & 0 \\
\hline S8 & 0 & 0 & 0 & 0 & 0 & 0 & 0 & 1 & 0 & 0 & 0 \\
\hline S9 & 0 & 0 & 0 & 0 & 0 & 0 & 0 & 0 & 1 & 1 & 0 \\
\hline S10 & 0 & 0 & 0 & 0 & 0 & 0 & 1 & 0 & 0 & 1 & 0 \\
\hline S11 & 0 & 1 & 0 & 0 & 0 & 1 & 0 & 0 & 0 & 0 & 1 \\
\hline
\end{tabular}




\subsection{FINAL REACHABILITY MATRIX}

The initial reachability matrix is checked for transitivity and then the final reachability matrix is constructed as shown in Table 3. Transitivity check is one of the crucial factors that determines the final structure of the ISM.It is done on all entries with zero $(0)$ in initial reachability matrix. Whenever there is a transitive relationship between strategies 0 is replaced by $1^{*}$.

This matrix summarizes the driving power and dependency of each strategy. Driving power for each strategy tested is the total number of strategies (including itself) that it may assist to achieve and is calculated by horizontal summation of the effect of one strategy on other strategy. On the other hand, the dependence highlights the total number of strategies (including itself) that it is dependent on and that helps in achieving it. It is calculated using vertical summation of the strategies.

TABLE 3: FINAL REACHABILITY MATRIX

\begin{tabular}{|c|c|c|c|c|c|c|c|c|c|c|c|c|}
\hline STRATEGY & S1 & s2 & S3 & $\$ 4$ & S5 & S6 & S7 & S8 & 59 & S10 & $S 11$ & $\begin{array}{l}\text { DRIVING } \\
\text { POWER }\end{array}$ \\
\hline S1 & 1 & 0 & 1 & 0 & $1^{*}$ & 0 & $1^{*}$ & $1^{*}$ & 0 & 0 & 0 & 5 \\
\hline S2 & 1 & 1 & 1 & 0 & $1^{*}$ & 1 & $1^{*}$ & $1^{*}$ & $1^{*}$ & $1^{*}$ & 1 & 10 \\
\hline S3 & 0 & 0 & 1 & 0 & $1^{*}$ & 0 & 1 & $1^{*}$ & 0 & 0 & 0 & 4 \\
\hline S4 & $1^{*}$ & 1 & $1^{*}$ & 1 & $1^{*}$ & $1^{*}$ & $1^{*}$ & $1^{*}$ & $1^{*}$ & $1^{*}$ & $1^{*}$ & 11 \\
\hline S5 & 0 & 0 & 0 & 0 & 1 & 0 & 0 & 1 & 0 & 0 & 0 & 2 \\
\hline S6 & 1 & 0 & $1^{*}$ & 0 & $1^{*}$ & 1 & $1^{*}$ & $1^{*}$ & 1 & $1^{*}$ & 0 & 8 \\
\hline S7 & 0 & 0 & 0 & 0 & 1 & 0 & 1 & $1^{*}$ & 0 & 0 & 0 & 3 \\
\hline S8 & 0 & 0 & 0 & 0 & 0 & 0 & 0 & 1 & 0 & 0 & 0 & 1 \\
\hline S9 & 0 & 0 & 0 & 0 & $1^{*}$ & 0 & $1^{*}$ & $1^{*}$ & 1 & 1 & 0 & 5 \\
\hline S10 & 0 & 0 & 0 & 0 & $1^{*}$ & 0 & 1 & $1^{*}$ & 0 & 1 & 0 & 4 \\
\hline S11 & $1^{*}$ & 1 & $1^{*}$ & 0 & $1^{*}$ & 1 & $1^{*}$ & $1^{*}$ & $1^{*}$ & $1^{*}$ & 1 & 10 \\
\hline Dependence & 5 & 3 & 6 & 1 & 10 & 4 & 9 & 11 & 5 & 6 & 3 & 63 \\
\hline
\end{tabular}

\subsection{LEVEL PARTITIONING}

The reachability and antecedent sets for each strategy are determined from the final reachability matrix. The reachability set consists of the strategy itself and other strategies to which it may help achieve while the antecedent set consists of the strategy itself and other strategies that may help achieving it. The intersection set of the antecedent and reachability sets for all strategies are calculated. The strategies for which the reachability and intersection sets are same becomes the top-level strategy in the ISM hierarchy. This strategy is then eliminated from other strategies. Then by the same iterative process, the next level of strategy is found and eliminated. This iteration is repeated till the levels of each strategy is determined which is used to frame the final model of ISM hierarchy. These iterations are shown from Table 4 to Table 11. 
TABLE 4: FIRST ITERATION

\begin{tabular}{|l|l|l|l|l|}
\hline STRATEGY & REACHABILITY SET & ANTECEDENT SET & INTERSECTION SET & LEVEL \\
\hline S1 & $1,3,5,7,8$ & $1,2,4,6,11$ & 1 & \\
\hline S2 & $1,2,3,5,6,7,8,9,10,11$ & $2,4,11$ & 2,11 & \\
\hline S3 & $3,5,7,8$ & $1,2,3,4,6,11$ & 3 & \\
\hline S4 & $1,2,3,4,5,6,7,8,9,10,11$ & 4 & 4 & \\
\hline S5 & 5,8 & $1,2,3,4,5,6,7,9,10,11$ & 5 & \\
\hline S6 & $1,3,5,6,7,8,9,10$ & $2,4,6,11$ & 6 & \\
\hline S7 & $5,7,8$ & $1,2,3,4,6,7,9,10,11$ & 7 & \\
\hline S8 & 8 & $1,2,3,4,5,6,7,8,9,10,11$ & 8 & Level 1 \\
\hline S9 & $5,7,8,9,10$ & $2,4,6,9,11$ & 9 & \\
\hline S10 & $5,7,8,10$ & $2,4,6,9,10,11$ & 10 & \\
\hline S11 & $1,2,3,5,6,7,8,9,10,11$ & $2,4,11$ & 2,11 & \\
\hline & & & & \\
\hline
\end{tabular}

TABLE 5: SECOND ITERATION

\begin{tabular}{|l|l|l|l|l|}
\hline STRATEGY & REACHABILITY SET & ANTECEDENT SET & INTERSECTION SET & LEVEL \\
\hline S1 & $1,3,5,7$ & $1,2,4,6,11$ & 1 & \\
\hline S2 & $1,2,3,5,6,7,9,10,11$ & $2,4,11$ & 2,11 & \\
\hline S3 & $3,5,7$ & $1,2,3,4,6,11$ & 3 & \\
\hline S4 & $1,2,3,4,5,6,7,9,10,11$ & 4 & 4 & \\
\hline S5 & 5 & $1,2,3,4,5,6,7,9,10,11$ & 5 & Level 2 \\
\hline S6 & $1,3,5,6,7,9,10$ & $2,4,6,11$ & 6 & \\
\hline S7 & 5,7 & $1,2,3,4,6,7,9,10,11$ & 7 & \\
\hline S9 & $5,7,9,10$ & $2,4,6,9,11$ & 9 & \\
\hline S10 & $5,7,10$ & $2,4,6,9,10,11$ & 10 & \\
\hline S11 & $1,2,3,5,6,7,9,10,11$ & $2,4,11$ & 2,11 & \\
\hline
\end{tabular}


TABLE 6: THIRD ITERATION

\begin{tabular}{|l|l|l|l|l|}
\hline STRATEGY & REACHABILITY SET & ANTECEDENT SET & INTERSECTION SET & LEVEL \\
\hline S1 & $1,3,7$ & $1,2,4,6,11$ & 1 & \\
\hline S2 & $1,2,3,6,7,9,10,11$ & $2,4,11$ & 2,11 & \\
\hline S3 & 3,7 & $1,2,3,4,6,11$ & 3 & \\
\hline S4 & $1,2,3,4,6,7,9,10,11$ & 4 & 4 & \\
\hline S6 & $1,3,6,7,9,10$ & $2,4,6,11$ & 6 & \\
\hline S7 & 7 & $1,2,3,4,6,7,9,10,11$ & 7 & Level 3 \\
\hline S9 & $7,9,10$ & $2,4,6,9,11$ & 9 & \\
\hline S10 & 7,10 & $2,4,6,9,10,11$ & 10 & \\
\hline S11 & $1,2,3,5,6,9,10,11$ & $2,4,11$ & 2,11 & \\
\hline & & & & \\
\hline
\end{tabular}

TABLE 7: FOURTH ITERATION

\begin{tabular}{|l|l|l|l|l|}
\hline STRATEGY & REACHABILITY SET & ANTECEDENT SET & INTERSECTION SET & LEVEL \\
\hline S1 & 1,3 & $1,2,4,6,11$ & 1 & \\
\hline S2 & $1,2,3,6,9,10,11$ & $2,4,11$ & 2,11 & \\
\hline S3 & 3 & $1,2,3,4,6,11$ & 3 & Level 4 \\
\hline S4 & $1,2,3,4,6,9,10,11$ & 4 & 4 & \\
\hline S6 & $1,3,6,9,10$ & $2,4,6,11$ & 6 & \\
\hline S9 & 9,10 & $2,4,6,9,11$ & 9 & \\
\hline S10 & 10 & $2,4,6,9,10,11$ & 10 & Level 4 \\
\hline S11 & $1,2,3,5,6,9,10,11$ & $2,4,11$ & 2,11 & \\
\hline
\end{tabular}

TABLE 8: FIFTH ITERATION

\begin{tabular}{|l|l|l|l|l|}
\hline STRATEGY & REACHABILITY SET & ANTECEDENT SET & INTERSECTION SET & LEVEL \\
\hline S1 & 1 & $1,2,4,6,11$ & 1 & Level 5 \\
\hline S2 & $1,2,6,9,11$ & $2,4,11$ & 2,11 & \\
\hline S4 & $1,2,4,6,9,11$ & 4 & 4 & \\
\hline S6 & $1,6,9$ & $2,4,6,11$ & 6 & \\
\hline S9 & 9 & $2,4,6,9,11$ & 9 & Level 5 \\
\hline S11 & $1,2,5,6,9,11$ & $2,4,11$ & 2,11 & \\
\hline
\end{tabular}




\begin{tabular}{|l|l|l|l|l|}
\hline STRATEGY & REACHABILITY SET & ANTECEDENT SET & INTERSECTION SET & LEVEL \\
\hline S2 & $2,6,11$ & $2,4,11$ & 2,11 & \\
\hline S4 & $2,4,6,11$ & 4 & 4 & \\
\hline S6 & 6 & $2,4,6,11$ & 6 & Level 6 \\
\hline S11 & $2,5,6,11$ & $2,4,11$ & 2,11 & \\
\hline
\end{tabular}

TABLE 10: SEVENTH ITERATION

\begin{tabular}{|l|l|l|l|l|}
\hline STRATEGY & REACHABILITY SET & ANTECEDENT SET & INTERSECTION SET & LEVEL \\
\hline S2 & 2,11 & $2,4,11$ & 2,11 & Level 7 \\
\hline S4 & $2,4,11$ & 4 & 4 & \\
\hline S1 & $2,5,11$ & $2,4,11$ & 2,11 & Level 7 \\
\hline & & & & \\
\hline
\end{tabular}

\section{TABLE 11: EIGHTH ITERATION}

\begin{tabular}{|l|l|l|l|l|}
\hline STRATEGY & REACHABILITY SET & ANTECEDENT SET & INTERSECTION SET & LEVEL \\
\hline S4 & 4 & 4 & 4 & Level 8 \\
& & & & \\
\hline
\end{tabular}

From Table 4, it can be observed that the strategy 'Economic Recovery' (S8) is at level 1. Thus, it will be positioned at the top of the ISM hierarchy. The strategy S8 does not lead to any other strategy and is subsequently removed in the next iteration leading to the next table. The Table 5 shows the strategy of 'resumption of economic activities and trade facilitation' (S5) does not lead to any other variable and is marked at level 2. Following that in Table 6 we will observe that the strategy of 'reducing community transmission through universal masking policy and optimal social distancing' (S7) does not lead to any other variable and is marked at level 3. Similarly, with the iteration in Table7, the strategy of 'social cooperation and trust' (S3) and 'augmenting healthcare infrastructure' (S10) do not lead to any other variable and so placed at level 4 while the strategies of 'financial emergency response plan (S1) and 'research and development in healthcare sector' (S9) in Table 8 forms the level 5 of the hierarchy. The strategy in Table 9 of 'graded surveillance - targeted restrictions and stricter norms for inter-state mobility' (S6) is marked at level 6.
The strategy of 'harmonization between centre, state and local authorities'(S2) and 'online awareness and capacity building programme' (S11) in Table 10 are marked at level 7 of the hierarchy. From the Table 11 the final level 8 is determined as the strategy of 'environmental sustainability and human well-being' (S4). This strategy is therefore the most dominant strategy.

\subsection{MICMAC ANALYSIS: CLASSIFICATION OF STRATEGIES}

Cross-impact matrix multiplication applied to classification (MICMAC) was developed to estimate the driving and dependence power of various inter-dependent variables. [38] The variables are plotted on a graph with dependence on $x$-axis and driving power on y-axis. Based on the dependence and driving powers of the strategies that have been calculated in the final reachability matrix, it is classified into four categories:

- Autonomous strategy (quadrantI)

The strategies with weak dependence power and weak driving power. In this study the strategy of 'financial 
emergency response plan' (S1), 'social cooperation and trust' (S3), 'research and development in healthcare sector' (S9) and 'Augmenting healthcare infrastructure' (S10) are observed to be autonomous. These strategies are relatively disconnected from the overall policy framework and tend to have no significant impact on other strategic interventions devised by the government.

- Dependent strategy (quadrant-II)

The strategies that have higher dependence on other variables but low driving power. In our analysis, the strategy of 'resumption of economic activities and trade facilitation' (S5), 'reducing community transmission through universal masking policy and optimal social distancing'(S7) and 'economic recovery'

(S8) are identified as dependent strategies. These variables get influenced when there is change in the other variables.

- Linkage strategy (quadrant-III)

The strategies that have a high dependence power and high driving power. In our study there are no linkage strategies.

- Driving or independent strategy (quadrant-IV)

Those strategies that have a high driving power, but low dependence power. Our analysis identifies strategy of 'harmonization between centre, state and local authorities' (S2), 'environmental sustainability and human well-being' (S4), 'graded surveillance- targeted restrictions and stricter norms for inter- state mobility' (S6) and 'online awareness and capacity building programme'(S11) as the driving strategies. The driver power-dependence diagram with four-segmented quadrants is depicted in Figure 1.

FIGURE 1: MICMAC ANALYSIS

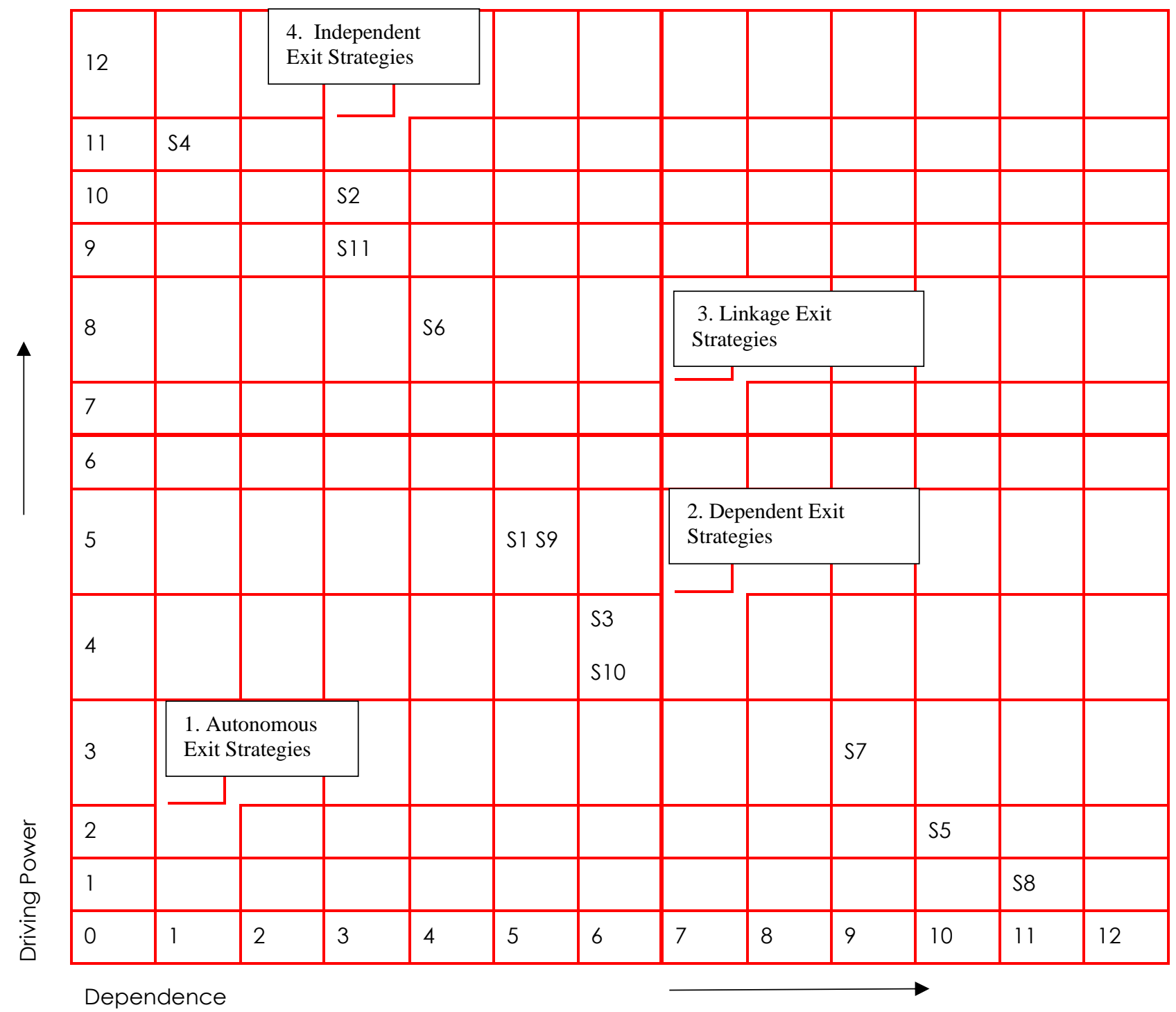


FIGURE 2: ISM HIERARCHY

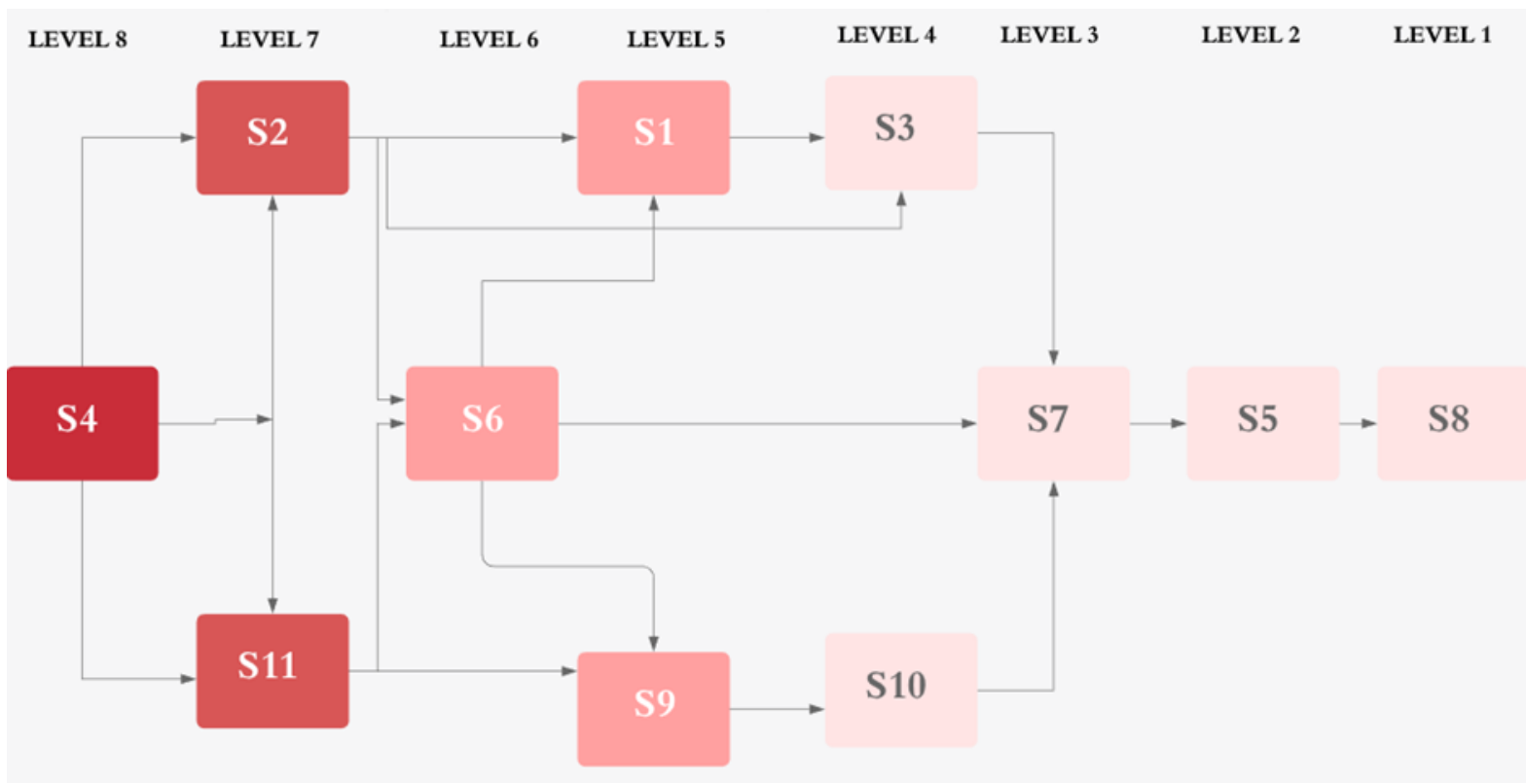

FIGURE 3: FINAL ISM HIERARCHY

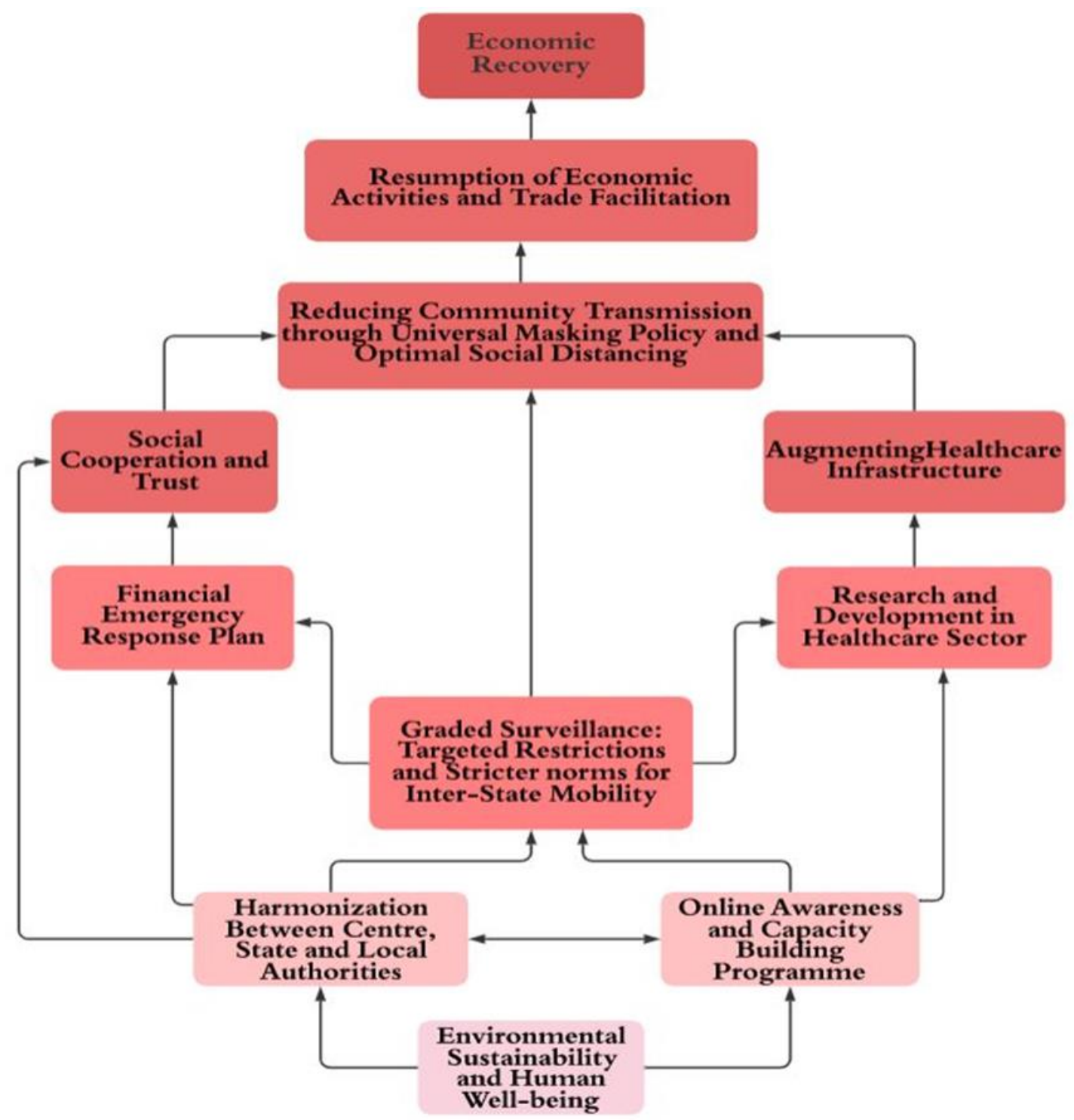




\subsection{FORMATION OF ISM HIERARCHY}

From the final reachability matrix, the diagraph of the varied strategy is evaluated and their inter-relationship with other strategies are depicted through the flowchart representation of the ISM hierarchy (Figure 2). If there is a relationship between the strategies $i$ and $j$ then it is depicted directional arrow which points from $\mathrm{i}$ to $\mathrm{j}$.

The ISM hierarchy developed is finally transformed into figure 3 which incorporates all the strategies and their interdependencies with other strategies based on their degree of effectiveness in the process of economic revival post the global lockdown period. It can be observed from the figure that four strategies namely 'environmental sustainability and human well-being' (S4), 'online awareness and capacity building programme (S11), graded surveillance -targeted restrictions and stricter norms for inter- state mobility' (S6) and 'harmonization between centre, state and local authorities' (S2) are the most important strategies with high driving powers. The remaining variables are dependent on these key strategies for minimising the economic downturn due to COVID 19.

\section{DISCUSSION AND CONCLUSION}

The COVID19 induced lockdown has severely impacted the economy primarily due to supply chain disruption, closure of industries and liquidity shocks. This has led policymakers to search for exit strategies to kick-start the economy and at the same time secure human well-being from falling prey to COVID 19. Keeping in mind the uncertainty of the present crisis and the need for an immediate exit plan, we have formulated a roadmap which can act as a guiding tool for policymakers.

Through our study, we have identified 11 key exit strategies through extensive literature review and expert opinion. The inter-relationships between various strategies based on their respective driving power and dependency were established using ISM and MICMAC approach. The levels of the ISM hierarchy were then evaluated through multiple iterations, the strategies which are placed at the bottom of the ISM diagraph have high driving powers while those at the top have higher dependencies.The results from the study suggest that strategy of 'environmental sustainability and human well-being' (S4) placed at level 8, has the highest driving power and is the most dominant strategy. Other significant strategies include- 'online awareness and capacity building program' (S11), 'harmonization between centre, state and local authorities' (\$2) which were placed level 7 and 'graded surveillance - targeted restrictions and stricter norms for inter-state mobility' (S6) placed at level 6 .

ISM diagraph is supported by MICMAC analysis in which these strategies have been placed in quadrant IV of MICMAC graph indicating the driving ability or economic significance of these strategies in mitigating the impact of COVID 19. The study can assist the government and policymakers in framing exit strategies evaluated in our model for devising an effective pandemic response plan.

\section{References:}

1. Coronavirus disease (COVID-19) Situation Report106, WHO 2020. Available from:

https://www.who.int/docs/default-

source/coronaviruse/situationreports/20200505covid-19-sitrep106.pdf? sfvrsn=47090f63_2

2. Usher, A. D. (2020). WHO launches crowdfund for COVID-19 response. The Lancet, 395(10229), 1024. doi:10.1016/s0140-6736(20)30719-4

3. Coronavirus Aid, Relief, and Economic Security Act or the CARES Act,

2020.https://www.congress.gov/bill/116thcongress/house-

bill/748? q=\%7B\%22search\%22\%3A\%5B\%22Coronav irus\%22\%5D\%7D\&s=3\&r=3

4. Béland, D., Lecours, A., Paquet, M., \&Tombe, T. (2020). A Critical Juncture in Fiscal Federalism? Canada's Response to COVID-19. Canadian Journal of Political Science, 1-5. doi:10.1017/S0008423920000323

5. Paquet, M., \&Schertzer, R. (2020). COVID-19 as a Complex Intergovernmental Problem. Canadian Journal of Political Science, 1-5. doi:10.1017/s0008423920000281

6. Perez, Victoria and Ross, Justin M., Federalism and Polycentric Government in a Pandemic (April 3 , 2020). Special Edition Policy Brief. Available at SSRN: https://ssrn.com/abstract $=3570726$ or http://dx.doi.org/10.2139/ssrn.3570726 
7. Social stigma associated with the coronavirus disease (COVID-19), UNICEF, 2020. Available from: https://www.unicef.org/documents/social-stigmaassociated-coronavirus-disease-covid-19

8. Logie, C. H., \&Turan, J. M. (2020). How Do We Balance Tensions Between COVID-19 Public Health Responses and Stigma Mitigation? Learning from HIV Research. AIDS and Behavior. doi:10.1007/s 10461-020-02856-8

9. Goldstein, Daniel A. N. and Wiedemann, Johannes, Who Do You Trust? The Consequences of Partisanship and Trust in Government for Public Responsiveness to COVID-19 Orders (April 19, 2020). Available at SSRN: https://ssrn.com/abstract $=3580547$ or http://dx.doi.org/10.2139/ssrn.3580547

10. Brooks, S. K., Webster, R. K., Smith, L. E., Woodland, L., Wessely, S., Greenberg, N., \& Rubin, G. J. (2020). The psychological impact of quarantine and how to reduce it: rapid review of the evidence. The Lancet. doi:10.1016/s01406736(20)30460-8

11. Li, Z., Ge, J., Yang, M., Feng, J., Qiao, M., Jiang, R., ... Yang, C. (2020). Vicarious traumatization in the general public, members, and non-members of medical teams aiding in COVID-19 control. Brain, Behavior, and Immunity. doi:10.1016/j.bbi.2020.03.007

12. Zhang, J., Lu, H., Zeng, H., Zhang, S., Du, Q., Jiang, T., \& Du, B. (2020). The differential psychological distress of populations affected by the COVID-19 pandemic. Brain, Behavior, and Immunity. doi:10.1016/j.bbi.2020.04.031

13. Earth Observatory, NASA, 2020. Available from: https://earthobservatory.nasa.gov/images

14. Hobbs, J. E. (2020). Food supply chains during the COVID-19 pandemic. Canadian Journal of Agricultural Economics/Revue CanadienneD'agroeconomie. doi:10.1111/cjag.12237

15. [Kerr, W. A. (2020). The COVID-19 pandemic and agriculture - Short and long run implications for international trade relations. Canadian Journal of Agricultural Economics/Revue CanadienneD' agroeconomie. doi:10.1111/cjag.12230
16. Gruszczynski, L. (2020). The Covid-19 Pandemic and International Trade: Temporary Turbulences or Paradigm Shift? European Journal of Risk Regulation, 1-6. doi:10.1017/err.2020.29

17. Evenett, S. J. (2020). Sicken Thy Neighbour: The Initial Trade Policy Response to COVID-19. The World Economy. doi:10.1111/twec.12954

18. Sirkeci, Ibrahim \&Yüceşahin, M. (2020). Coronavirus and Migration: Analysis of Human Mobility and the Spread of COVID-19. Migration Letters. 17. 379-398. 10.33182/ml. v17i2.935.

19. Ding, Y., Luo, S., Zheng, X., Ling, P., Yue, T., Liu, Z., and Weng, J. (2020). Association between population migration and epidemic control of coronavirus disease 2019. Sci China Life Sci 63, https://doi.org/10.1007/s1 1427-020-1695-5

20. M. Chinazzi et al. (2020), Science, https://doi.org/10.1126/science.aba9757

21. Transmission of Coronavirus Disease 2019 (COVID19). Centers for Disease Control and Prevention. https://www.cdc.gov/coronavirus/2019ncov/prepare/transmission.html; March 4, 2020 , Accessed date: 22 March 2020.

22. Sen-Crowe, B., McKenney, M., \&Elkbuli, A. (2020). Social distancing during the COVID-19 pandemic: Staying home save lives. The American Journal of Emergency Medicine. doi:10.1016/j.ajem.2020.03.063

23. Gandhi, M., \&Havlir, D. (2020). The Time for Universal Masking of the Public for COVID-19 is Now. Open Forum Infectious Diseases. doi:10.1093/ofid/ofaa131

24. Keshtkar-Jahromi M, Sulkowski M, HolakovieNaieni K. Public Masking: An Urgent Need to Revise Global Policies to Protect against Novel Coronavirus Disease (COVID-19). The American Journal of Tropical Medicine and Hygiene. 2020 Apr. DOI: 10.4269/ajtmh.20-0305.

25. Herrero, A. G. (2020). The Pandemic Requires a Coordinated Global Economic Response. Intereconomics, 55(2), 66-67. doi:10.1007/s10272020-0871-7

26. Jonathan Michie (2020) The covid-19 crisis - and the future of the economy and economics, International Review of Applied Economics, 34:3, 301-303, DOI:10.1080/02692171.2020.1756040 
27. Binlei Gong, Shurui Zhang, Lingran Yuan \& Kevin Z. Chen (2020): A balance act: minimizing economic loss while controlling novel coronavirus pneumonia, Journal of Chinese Governance, DOI: 10.1080/23812346.2020.1741940

28. Vaughan, A. (2020). World braces for economic impact. New Scientist, 245(3272), 10.

doi:10.1016/s0262-4079(20)30477-2

29. COVID-19: vaccine research \& development. CBD Blog, 2020. Available from: https://medium.com/alphagreen/covid-19vaccine-research-development-369ffa4079ca

30. Zhou, Y., Hou, Y., Shen, J. et al. Network-based drug repurposing for novel coronavirus 2019 nCoV/SARS-CoV-2. Cell Discov 6, 14 (2020). https://doi.org/10.1038/s41421-020-0153-3

31. Rodriguez-Llanes JM, Castro Delgado R, Pedersen MG, Arcos González P \&MeneghiniM.Confronting COVID-19: Surging critical care capacity in Italy. [Submitted]. Bull World Health Organ. E-pub: 6 April 2020. doi: http://dx.doi.org/10.2471/BLT.20.257766

32. Kapoor, A., Guha, S., Kanti Das, M., Goswami, K. C., \& Yadav, R. (2020). Digital Healthcare: The only solution for better healthcare during COVID19 pandemic? Indian Heart Journal. doi:10.1016/j.inj.2020.04.001

33. Merchant, R. M., \& Lurie, N. (2020). Social Media and Emergency Preparedness in Response to Novel Coronavirus. JAMA. doi:10.1001/jama.2020.4469

34. Bin Arif, T., \& Ali, A. (2020). Harmonizing the COVID-19 cacophony: People need guidance. Infection Control \& Hospital Epidemiology, 1-6. doi:10.1017/ice.2020.105

35. ACS Cent. Sci. 2020, 6, 315-331. https://dx.doi.org/10.1021/acscentsci.0c00272?ref $=p d f$

36. Warfield, J.N. 1973. Binary matrices in system modeling. IEEE Trans. Man Cybernetics 3(5):441-9. http://ieeexplore.ieee.org/xpls/abs_all.jsp?arnum ber $=4309270$.

37. S. Lakshmi Priyadarsini\& M. Suresh (2020): Factors influencing the epidemiological characteristics of pandemic COVID 19: A TISM approach, International Journal of Healthcare Management, DOI: $10.1080 / 20479700.2020 .1755804$
38. Godet, M. (1993). From anticipation to action: a handbook of strategic prospective. Paris: UNESCO. 